\title{
GIS-SUPPORTED MAPPING OF SUITABLE PARKING AREAS USING AHP METHOD: THE CASE OF KONYA
}

\author{
T. Alkan ${ }^{1, *}$, S.S. Durduran ${ }^{1}$ \\ ${ }^{1}$ Necmettin Erbakan University, Faculty of Engineering, Geomatics Engineering, Konya, Turkey- tansualkan93@ gmail.com- \\ durduran2001@gmail.com
}

KEY WORDS: Parking Areas, Site Selection, Spatial Analysis, Geographic Information System, Analytical Hierarchy Process.

\begin{abstract}
:
The increase in the number of vehicles with the increasing population has caused the problem of parking insufficiency. This problem necessitate situation analysis of existing parking areas and site selection analyses for new parking areas. It is possible to make suitable site selections with spatial analysis supported by Geographic Information System (GIS). In this study, available parking areas in Selçuklu district of Konya province were evaluated and suitable parking areas were determined in line with the needs. The criteria affecting the parking areas site selection were determined and the importance levels of the criteria were detected by using the Analytical Hierarchy Process (AHP) which is one of the Multi-Criteria Decision Making (MCDM) methods. Density analyses were carried out with GIS and suitable parking areas map was produced considering the criteria weights obtained.
\end{abstract}

\section{INTRODUCTION}

With the rapidly increasing population and migration from the village to the city, many problems are encountered in the cities. One of these problems is the parking problem. The parking problem affects the traffic density and flow rate, thus affecting the transportation network (Gülhan and Ceyhan, 2010). It is not enough to solve this problem that the strategies implemented by local governments in the spatial planning process offer singular solutions (Öztürk and Işınkaralar, 2019). Therefore, parking policies should be determined by local governments (Atalay and İçen, 2020).

Transportation is a rapidly growing field that has an important place in human life. With the rapid growth of cities and increasing population, problems in urban transportation have increased. One of the most important factors in the success and efficiency of urban land uses is easy access to parking facilities (Aliniai et al., 2015). This has made the selection of suitable parking spaces more important. Site selection requires consideration of many criteria (Öztürk and Kılıç-Gül, 2020). The AHP method, which is one of the MCDM methods and evaluates many qualitative and quantitative criteria together, is an effective method in solving site selection problems. At the same time, GIS technologies used for parking lot selection have the ability to analyse many criteria (Farzanmanesh et al., 2010).

AHP method and GIS technologies offer effective solutions in choosing the suitable parking areas. In this study, GIS supported AHP method was used for the selection of suitable parking areas in Selçuklu district of Konya province. First of all, the criteria affecting the parking areas selection were determined. In order to evaluate the criteria, a questionnaire was prepared and expert opinions were taken. The results of the questionnaire were examined and the criteria weights were determined. With GIS technologies, the position of each criterion in the study area was determined and density analyses were made. Suitable parking areas were determined by taking into account the criteria weights obtained.

\section{MATERIAL AND METHOD}

\subsection{Material}

This study was carried out in Selçuklu district of Konya province (Figure 1). Zoning plans and satellite images were used in this study to determine suitable parking areas.

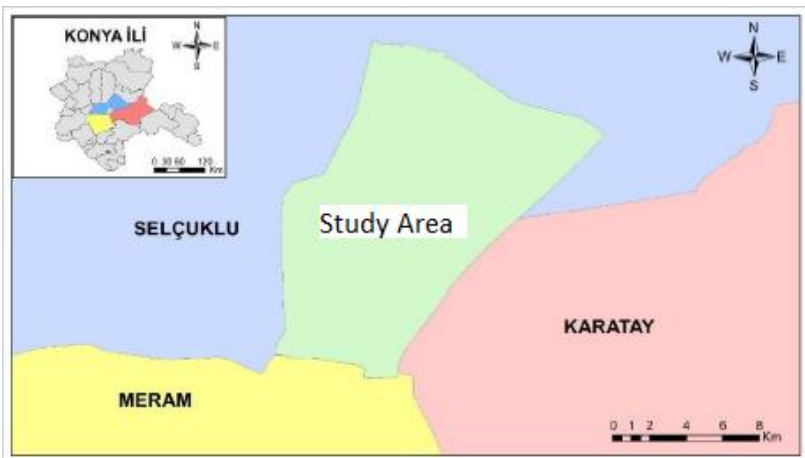

Figure 1. Study area

In this study, AHP method was used to determine suitable parking areas. AHP method is based on pairwise comparison matrices. The criteria are mutually compared and their importance levels are obtained relative to each other. In the AHP method, a hierarchical structure is first created. The purpose, main criteria, sub-criteria and alternatives are determined. The main criteria in this study are; land use and transportation. Land use sub-criteria; proximity to shopping malls, proximity to health facilities, proximity to social and cultural facilities, proximity to educational facilities, proximity to public facilities and proximity to market places. Transportation sub-criteria are proximity to main roads, proximity to tram stops and proximity to existing parking areas. In order to determine the criteria weights, a questionnaire was prepared in accordance with the AHP method and the opinions of experts were taken. 
The criteria used in the selection of parking areas were determined by considering the needs and characteristics of the study area. In addition, (Farzanmanesh et al., 2010), (Alinia et al., 2015) (Jelokhani-Niaraki and Malczewski, 2015), (Demir, 2016), (Kulinich and Lee, 2016), (Iqbal, 2020) and (Ozturk and Kilic-Gul, 2020) was used as a reference to determine the criteria.

The criteria affecting the determination of suitable parking areas were determined by using the zoning plan and Konya Urban Information System. The locations of these criteria within the study area were determined to realise spatial analysis. Density analyses of the criteria were realised using GIS and a suitability map was produced according to the criteria weights obtained with AHP.

\subsection{Method}

AHP method, which is one of the MCDM methods, was used to determine suitable parking areas. The AHP method was first proposed by Myers and Alpert in 1968 and was developed by Saaty in 1977. The AHP method is a mathematical method that evaluates qualitative and quantitative criteria together, based on expert opinions in decision making problems.

The application steps of the AHP method are as follows (Saaty, 2008):

Establishing the Hierarchical Structure: Purpose, criteria and alternatives are determined.

The hierarchical structure created in this study is given in Figure 2.

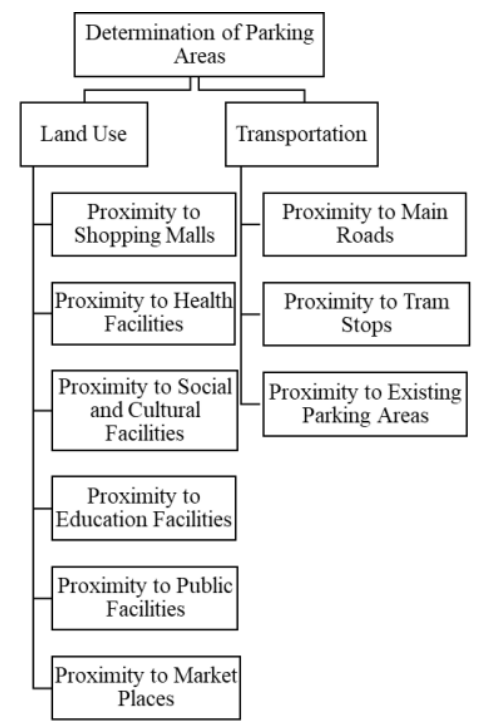

Figure 2. Hierarchical structure of criteria

Construction of Pairwise Comparison Matrices: Pairwise comparison matrices are created for each criterion. The scale used in the pairwise comparison of the criteria is given in Table 1.

Table 1. Pairwise comparison scale in AHP method (Saaty, 2008)

\begin{tabular}{lll}
\hline $\begin{array}{l}\text { Importance } \\
\text { Scale }\end{array}$ & Definition & Explanation \\
\hline 1 & Equal importance & $\begin{array}{l}\text { Two activities contribute } \\
\text { equally to the objective }\end{array}$
\end{tabular}

3 Moderate Experience and judgement importance slightly favour one activity over another

$5 \quad$ Strong importance Experience and judgement strongly favour one activity over another

7 Very strong An activity is favoured very importance strongly over another

Extreme The evidence favouring one importance activity over another is of the highest possible order of affirmation

2,4,6,8 Intermediate Values between two values consecutive judgments to be used when compromise is needed

Calculation of Weights for Criteria: Pairwise comparison matrices are created (1). Each value is divided by the column total to which it belongs (2). W column vector is calculated by taking the average of the values in each row of the obtained matrix (3).

$A=\left[a_{i j}\right]=\left[\begin{array}{ccccc}1 & a_{12} & a_{13} & \cdots & a_{1 n} \\ 1 / a_{12} & 1 & a_{23} & \cdots & a_{2 n} \\ 1 / a_{13} & 1 / a_{23} & 1 & \cdots & a_{3 n} \\ \cdots & \cdots & \cdots & \cdots & \cdots \\ 1 / a_{1 n} & 1 / a_{2 n} & 1 / a_{3 n} & \cdots & 1\end{array}\right]$ (1)

$c_{i j}=\frac{a_{i j}}{\sum_{i=1}^{n} a_{i j}}$ (2) $W_{i}=\frac{\sum_{j=1}^{n} c_{i j}}{n}(3)$

Calculation of the Consistency Ratio: First, the comparison matrix A is multiplied by the column vector $\mathrm{W}$ and the column vector D is obtained (4). The elements of the column vector D and the column vector $\mathrm{W}$ are mutually divided (5) and the arithmetic average is taken (6). So $\lambda$ is calculated.

$$
\begin{aligned}
& D=\left\lfloor a_{i j}\right\rfloor \times\left\lfloor w_{i}\right\rfloor=\left\lfloor d_{i}\right\rfloor \quad \text { (4) } \\
& E_{i}=\frac{d_{i}}{w_{i}} \text { (5) } \quad \lambda=\frac{\sum_{i=1}^{n} E_{i}}{n} \text { (6) }
\end{aligned}
$$

After $\lambda$ is calculated, the Consistency Index (CI) is calculated (7). CR is obtained by dividing the CI value by the Random Index (RI) value given in Table 2 (8).

$$
C I=\frac{\lambda-n}{n-1} \quad \text { (7) } C R=\frac{C I}{R I}
$$

Table 2. Random Index (Saaty, 1980)

\begin{tabular}{cccccccc}
\hline $\mathrm{n}$ & 1 & 2 & 3 & 4 & 5 & 6 & 7 \\
\hline $\mathrm{RI}$ & 0.00 & 0.00 & 0.58 & 0.90 & 1.12 & 1.24 & 1.32 \\
\hline $\mathrm{n}$ & 8 & 9 & 10 & 11 & 12 & 13 & 14 \\
\hline $\mathrm{RI}$ & 1.41 & 1.45 & 1.49 & 1.51 & 1.48 & 1.56 & 1.57 \\
\hline
\end{tabular}




\section{RESULTS}

GIS supported AHP method was used in this study in which suitable parking areas were selected. With the AHP method, the weights of the criteria that are effective in the selection of suitable parking areas were determined. The basis of the AHP method is the mutually comparison of the criteria according to the 1-9 importance scale. A questionnaire was prepared in accordance with this importance scale and experts consisting of engineers and city planners were asked to evaluate the criteria.
The results of the questionnaires applied to 30 people were evaluated in the Expert Choice program. 15 questionnaires that were inconsistent were ignored. The remaining 15 questionnaires were evaluated and criteria weights were determined. In the Expert Choice program, the geometric average of the expert opinions is taken, and pairwise comparison matrices are created and the weights of the criteria are determined. The criteria weights obtained are given in Table 3.

Table 3. Weights of criteria

\begin{tabular}{|c|c|c|c|c|c|}
\hline \multicolumn{2}{|c|}{ Weights of Main Criteria } & \multicolumn{2}{|c|}{ Weights of Land Use Sub-Criteria } & \multicolumn{2}{|c|}{ Weights of Transportation Sub-Criteria } \\
\hline $\mathrm{CR}=0.00$ & W & $\mathrm{CR}=0.01$ & W & $\mathrm{CR}=0.01$ & W \\
\hline Land Use & 0.58 & $\begin{array}{l}\text { Proximity to } \\
\text { Shopping Malls }\end{array}$ & 0.119 & $\begin{array}{l}\text { Proximity to } \\
\text { Main Roads }\end{array}$ & 0.442 \\
\hline Transportation & 0.42 & $\begin{array}{l}\text { Proximity to } \\
\text { Health Facilities }\end{array}$ & 0.357 & $\begin{array}{l}\text { Proximity to } \\
\text { Tram Stops }\end{array}$ & 0.249 \\
\hline & & $\begin{array}{l}\text { Proximity to } \\
\text { Social and } \\
\text { Cultural Facilities }\end{array}$ & 0.088 & $\begin{array}{l}\text { Proximity to } \\
\text { Existing Parking } \\
\text { Areas }\end{array}$ & 0.308 \\
\hline & & $\begin{array}{l}\text { Proximity to } \\
\text { Educational } \\
\text { Facilities }\end{array}$ & 0.124 & & \\
\hline & & $\begin{array}{l}\text { Proximity to } \\
\text { Public Facilities }\end{array}$ & 0.165 & & \\
\hline & & $\begin{array}{l}\text { Proximity to } \\
\text { Market Places }\end{array}$ & 0.148 & & \\
\hline
\end{tabular}

MCDM methods and GIS can be used together in decision making problems. Using GIS, the locations of the criteria were determined and density analyses were performed.

\subsection{Land Use Sub-Criteria}

\section{Shopping Malls Density Analysis}

Kernel density map was produced by using point location data of shopping malls and classified according to density degree (Figure 3).

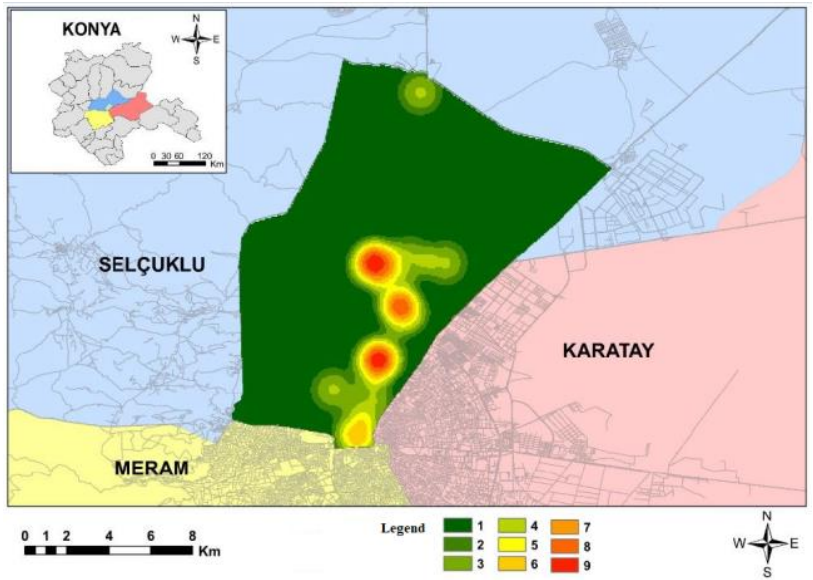

Figure 3. Shopping mall density analysis

Health Facilities Density Analysis

Kernel density map was produced by using point location data of health facilities and classified according to density degree (Figure 4).

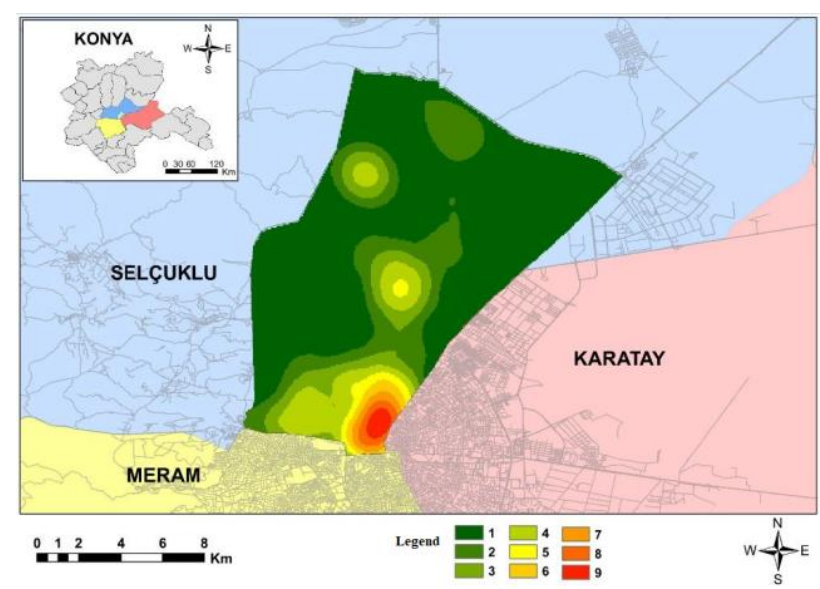

Figure 4. Health facilities density analysis

Social and Cultural Facilities Density Analysis Kernel density map was produced by using point location data of social and cultural facilities and classified according to density degree (Figure 5). 


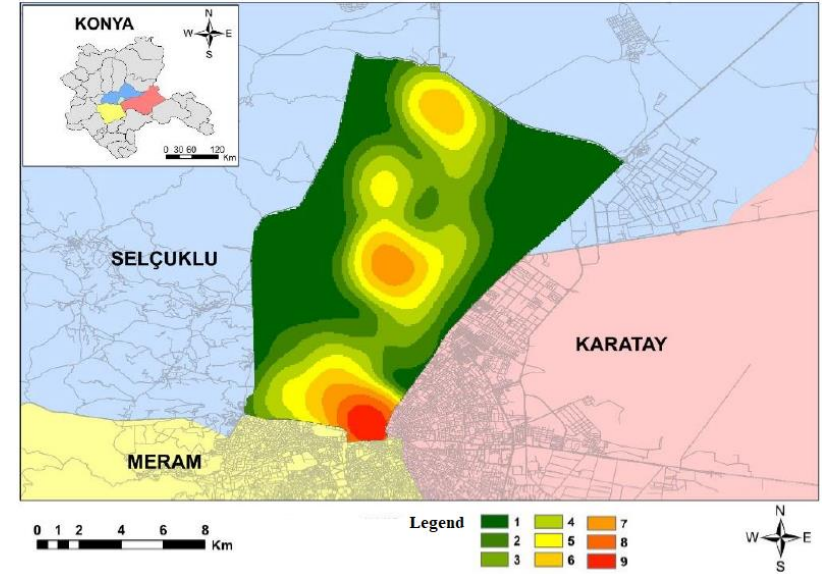

Figure 5. Social and cultural facilities density analysis

Educational Facilities Density Analysis

Kernel density map was produced by using point location data of educational facilities and classified according to density degree (Figure 6).

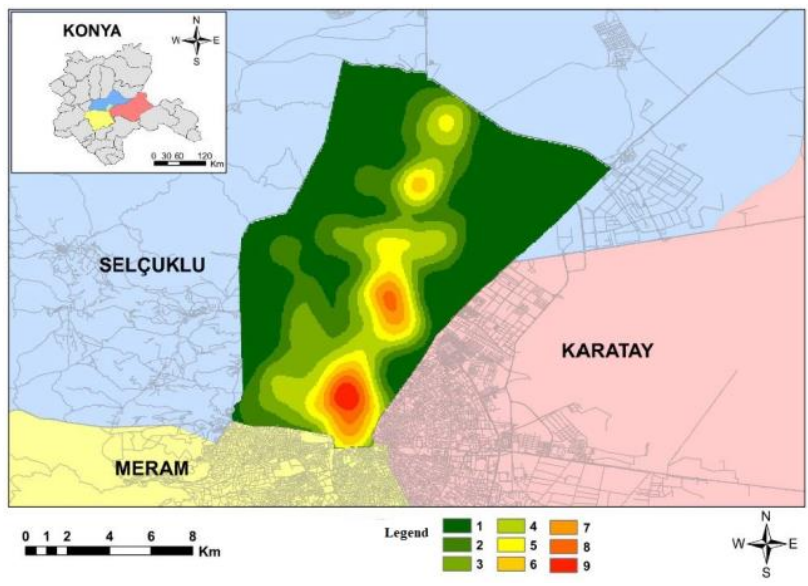

Figure 6. Educational facilities density analysis

\section{Public Facilities Density Analysis}

Kernel density map was produced by using point location data of public facilities and classified according to density degree (Figure 7).

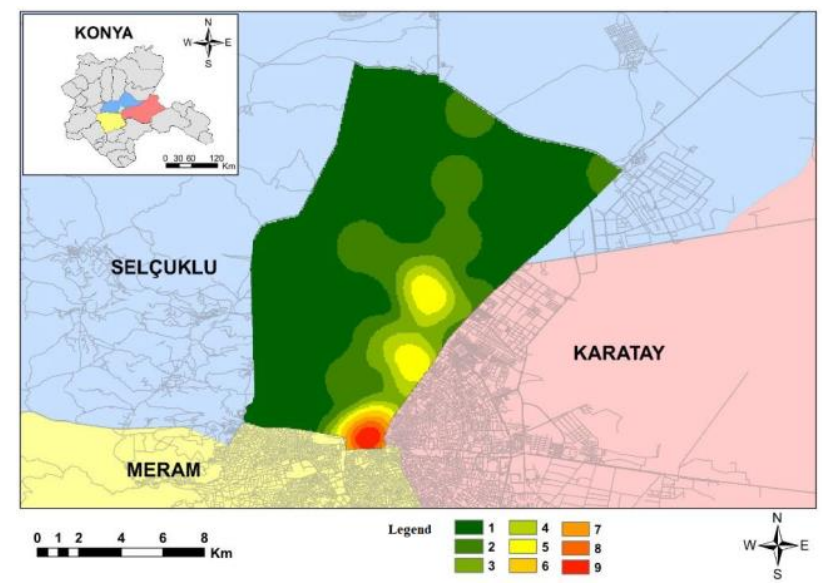

Figure 7. Public facilities density analysis

\section{Market Places Density Analysis}

Kernel density map was produced by using point location data of market places and classified according to density degree (Figure 8).

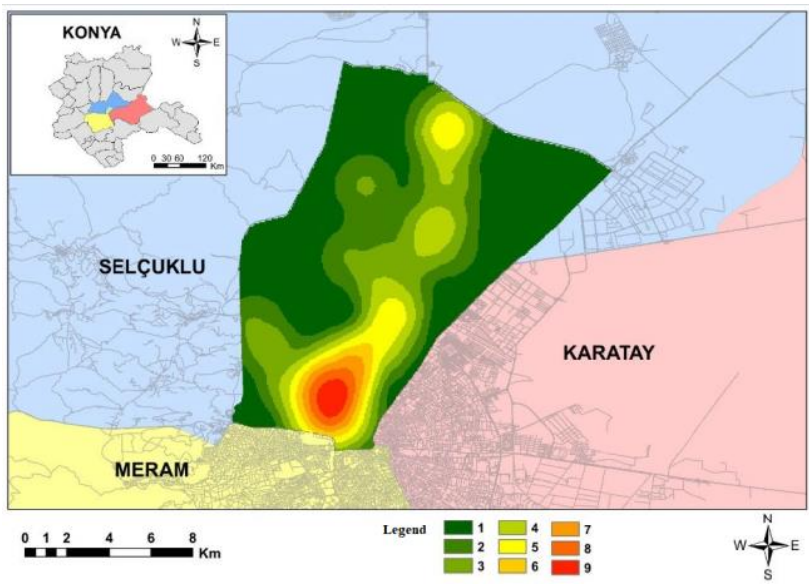

Figure 8. Market places density analysis

\subsection{Transportation Sub-Criteria}

Main Roads Density Analysis

Linear density map was created using the linear location data of the main roads and classified according to the degree of density (Figure 9).

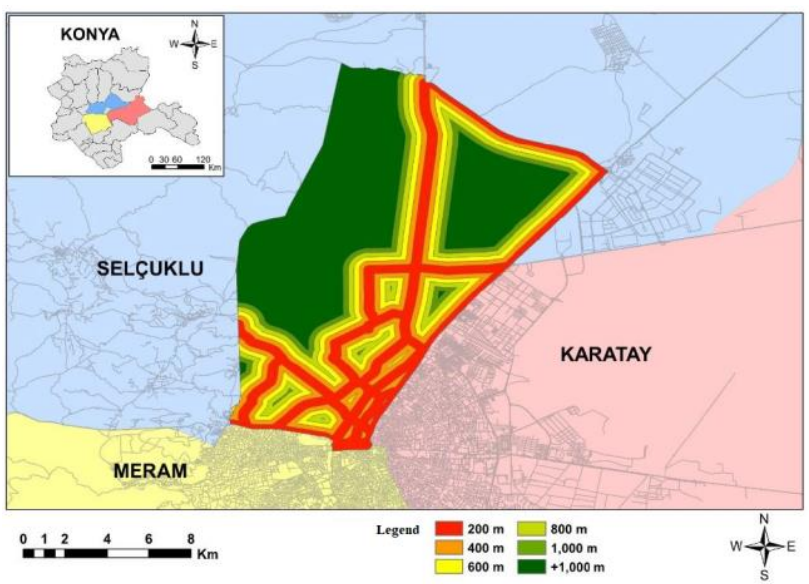

Figure 9. Main roads density analysis

Tram Stops Density Analysis

Linear density map was created using the linear location data of the tram stops and classified according to the degree of density (Figure 10). 


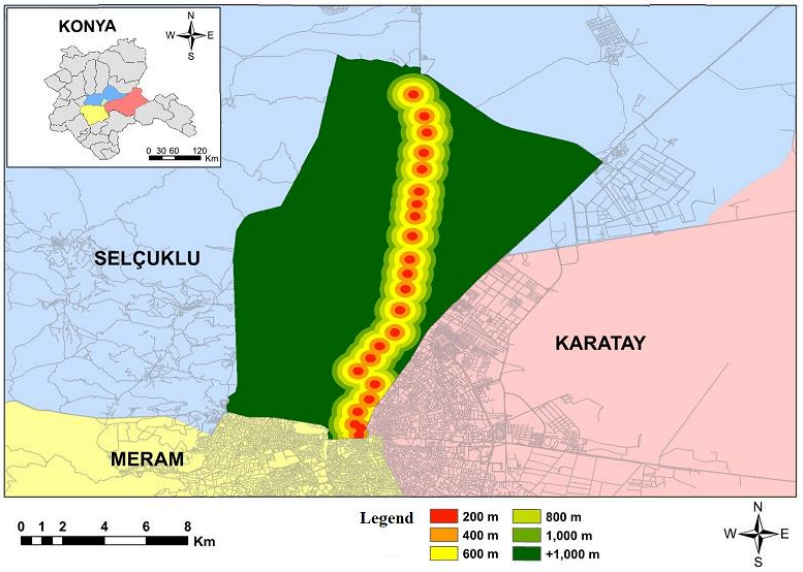

Figure 10. Tram stops density analysis

Existing Parking Areas Density Analysis

Kernel density map was produced by using point location data of existing parking areas and classified according to density degree (Figure 11).

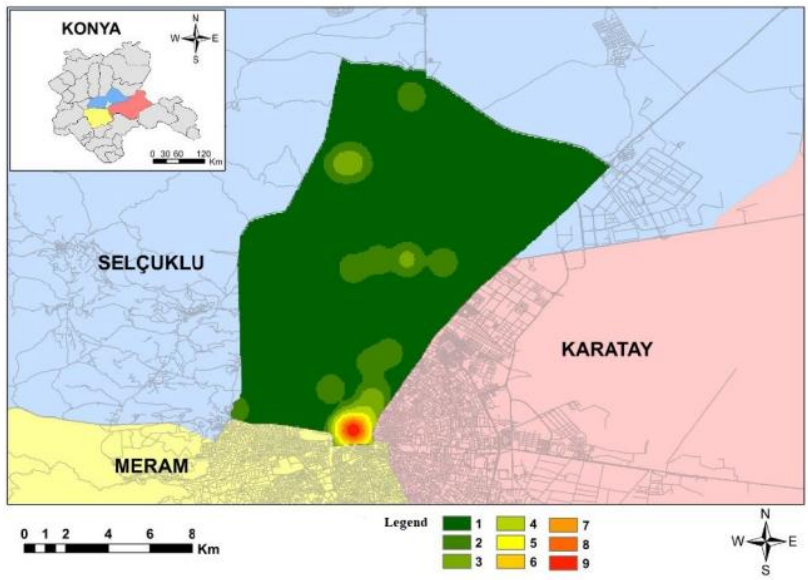

Figure 11. Existing parking areas density analysis

\section{CONCLUSION}

AHP method, which evaluates qualitative and quantitative data together, is frequently used in suitable site selection analyses. In the AHP method, it is determined to what extent the criteria affect the site selection by taking expert opinions. The criteria weights are calculated by creating pairwise comparison matrices. By calculating the consistency ratio, the consistency of the transactions is tested. In this study, a questionnaire was conducted and 15 expert opinions were evaluated in the Expert Choice program. The weights of land use and transportation criteria and the sub-criteria of these criteria are calculated and given in Table 3. A conversion was made between the main criteria and sub-criteria, and the criteria weights used in the production of the suitable parking areas location map are given in Figure 12.

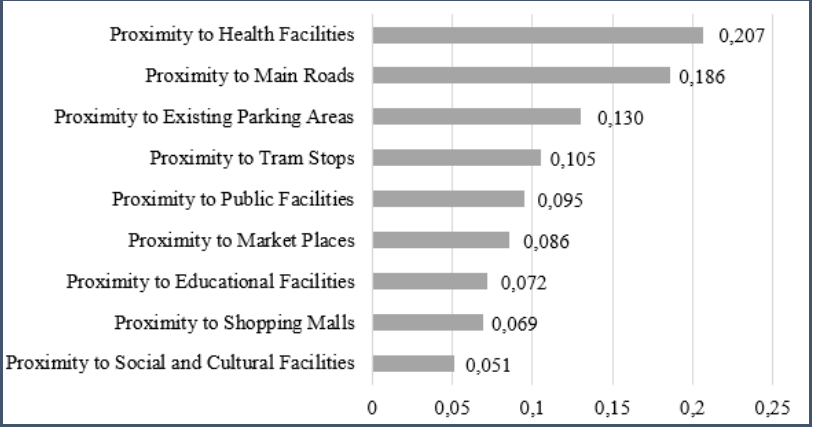

Figure 12. Weights of criteria

The criterion with the highest weight is the criterion of proximity to health facilities with 0.207 . The criterion with the lowest weight is the criterion of proximity to social and cultural facilities with 0.051 . Other criteria weights are as follows: proximity to main roads $(0.186)$, proximity to existing parking areas $(0.130)$, proximity to tram stops 0.105 , proximity to public facilities $(0.095)$, proximity to market places $(0.086)$, proximity to educational facilities $(0.072)$ and proximity to shopping malls (0.069). Consistency ratios obtained are less than 0.10 and the results are consistent.

Criteria locations were determined and density analyzes were performed for each criterion with GIS. Obtained raster data are classified. The result map was produced with a raster calculator using the criteria weights given in Figure 12. This map produced shows the suitable parking areas in Selçuklu district of Konya province (Figure 13).

According to Figure 13, the area covering Nișantaş1 and Ferhuniye Neighborhoods, Makro market, Municipality, Numune hospital and business centers is seen as the most suitable parking areas with the highest grade.

AHP method is a frequently used method in site selection problems. With this method, the importance levels of the criteria affecting the site selection problems are determined by taking expert opinions. By using spatial decision support systems, criterion weights are evaluated together and suitable site selection analysis is made. In this study, the AHP method was used together with spatial decision support systems, the weights of the criteria affecting the suitable parking areas site selection analysis were calculated and the suitable parking areas were determined. 


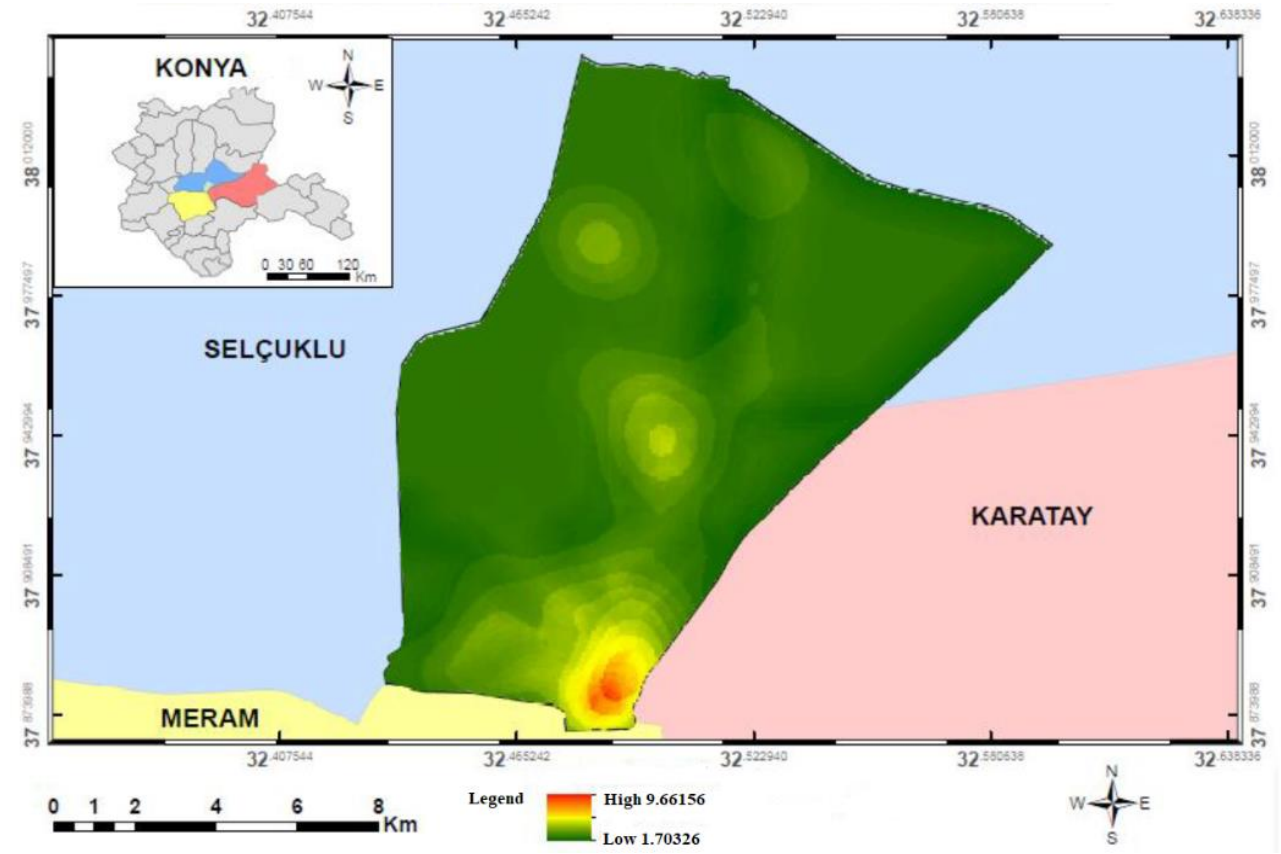

Figure 13. Suitable parking areas

\section{REFERENCES}

Aliniai, A., Yarahmadi, A., Zarin, J. Z., Yarahmadi, H., Lak, S. B., 2015: Parking Lot Site Selection: An Opening Gate Towards Sustainable GIS-based Urban Traffic Management. Journal of the Indian Society of Remote Sensing, 43(4), 801813.

Atalay, A., İçen, Y., 2020: Urban Parking Analysis, A Case Study: Elazı ̆ Province. Firat University Journal of Engineering Sciences, 32(2), 403-413.

Demir, S., 2016: Use of The Spatial Multiple Criteria Decision Making Techniques In The Selection Of Car Parking Area. Master Thesis, Yıldız Technical University, İstanbul.

Farzanmanesh A., Naeeni A.G., Abdullah A.M., 2010: Parking Site Selection Management Using Fuzzy Logic And Multi Criteria Decision Making. Environment Asia 3,109-116.

Gülhan, G., Ceylan, H., 2010: Parking Management Based Approach On Parking Problem: Example Of İzmir. Dokuz Eylül University Faculty Of Engineering Journal Of Engineering Sciences, 12(1), 63-73.

Iqbal, A.S., 2020: A GIS-Based Parking Demand Analysis and Site Selection for Parking Area: Pendik-İstanbul Case. Master Thesis, Gebze Technical University, Gebze.

Kulinich, I., Lee, H., 2016: Parking Site Selection in Downtown of Khabarovsk City Using GIS. International Journal of Smart Home, 10(4), 15-24.

Jelokhani-Niaraki, M., Malczewski, J., 2015: A group multicriteria spatial decision support system for parking siteselection problem: A case study. Land Use Policy, 42, 492508
Öztürk, S., Işınkaralar, Ö., 2019: Parking Problematique in Kastamonu City Center: A Critical Evaluation. The Journal of International Social Research, 12(67), 506-511.

Öztürk, D., Kılıç-Gül, F. 2020: GIS-based multi-criteria decision analysis for parking site selection. Kuwait Journal of Science, 47(3), 2-14.

Saaty, T.L., 1980: The Analitic Hierarchy Process, McGrawHill, New York.

Saaty, T.L., 2008: Decision Making with The Analytic Hierarchy Process, Int. J. Services Sciences, 1(1), 83-98. 